NBER WORKING PAPER SERIES

\title{
WHY DO PEOPLE VOLUNTEER? AN EXPERIMENTAL ANALYSIS OF PREFERENCES FOR TIME DONATIONS
}

\author{
Alexander L. Brown \\ Jonathan Meer \\ J. Forrest Williams \\ Working Paper 19066 \\ http://www.nber.org/papers/w19066
}

\author{
NATIONAL BUREAU OF ECONOMIC RESEARCH \\ 1050 Massachusetts Avenue \\ Cambridge, MA 02138 \\ May 2013
}

We would like to thank the Texas A\&M Humanities and Social Science Enhancement of Research Capacity Program, Texas A\&M College of Liberal Arts Seed Grant Program, and the College of Liberal Arts at Texas A\&M for providing generous financial support for our research. We have benefited from comments by Catherine Eckel, Ericka Farret, Judd Kessler, Rodrigo Velez and seminar participants at Chapman University, George Mason University, the University of California, San Diego, Washington State University, and conference presentations at 2013 Biennial Social Dilemmas Conference, the 2013 Stanford Institute for Theoretical Economics, and the 2012 and 2013 North American Economic Science Association Meetings. We would also like to thank Xiaoyuan Wang and Jeremy West for helping to conduct the sessions. The views expressed herein are those of the authors and do not necessarily reflect the views of the National Bureau of Economic Research.

NBER working papers are circulated for discussion and comment purposes. They have not been peer-reviewed or been subject to the review by the NBER Board of Directors that accompanies official NBER publications.

(C) 2013 by Alexander L. Brown, Jonathan Meer, and J. Forrest Williams. All rights reserved. Short sections of text, not to exceed two paragraphs, may be quoted without explicit permission provided that full credit, including $(\odot$ notice, is given to the source. 
Why Do People Volunteer? An Experimental Analysis of Preferences for Time Donations Alexander L. Brown, Jonathan Meer, and J. Forrest Williams

NBER Working Paper No. 19066

May 2013, Revised March 2016

JEL No. D64,H41

\begin{abstract}
Why do individuals volunteer their time even when recipients receive far less value than the donor's opportunity cost? Previous models of altruism that focus on the overall impact of a gift cannot rationalize this behavior, despite its prevalence. We develop a model that relaxes this assumption, al- lowing for differential warm glow depending on the form of the donation. In a series of laboratory experiments that control for other aspects of volunteering, such as its signaling value, subjects demonstrate behavior consistent with the theoretical assumption that gifts of time produce greater utility than the same transfers in the form of money. Subjects perform an effort task, accruing earnings at potentially different wage rates for themselves or a charity of their choice, with the ability to transfer any of their personal earnings to charity at the end of the experiment. Subjects exhibit strong preferences for donating time even when differential wage rates make it costly to do so. The results provide new insights on the nature of volunteering and gift-giving.

Alexander L. Brown

Department of Economics

TAMU 4228

College Station, TX 77843

abrown@econmail.tamu.edu

Jonathan Meer

Department of Economics

TAMU 4228

College Station, TX 77843

and NBER

jmeer@econmail.tamu.edu

J. Forrest Williams

Department of Economics

TAMU 4228

College Station, TX 77843

jwilliams@econmail.tamu.edu
\end{abstract}




\section{Introduction}

When a consultant whose hourly rate is $\$ 100$ donates her time at a local soup kitchen, it is unlikely that the kitchen is getting $\$ 100$ per hour worth of increased service provision. Yet this was the opportunity cost of the donation. The charity would be better served if the consultant had worked an extra hour and donated her extra salary to them. Further, her opportunity cost would have been identical. Indeed, in most charitable giving models, an altruistic donor would maximize the benefit of her donation to the organization subject to her personal costs.

The experiments in this paper are inspired in part by the observation that many high earners do, in fact, volunteer their time. ${ }^{1}$ Our hypothesis is that this phenomenon is driven, at least in part, by higher levels of warm glow when volunteering than when donating money, and we develop a theoretical model that generates testable implications on this point. This hypothesis does not preclude signaling or networking impacts on volunteering from being substantial; rather, we argue that, even in the absence of other-signaling opportunities, individuals still prefer to make gifts of time to those of money. Our experimental design controls wage rates and tasks, and keeps donative choices private to directly test whether individuals gain different levels of utility from donating money to charity and working an equiv-

\footnotetext{
${ }^{1}$ For example, data from the 2011 American Time Use Survey shows that, among full-time workers over 25 years of age, volunteer rates are similar across quartiles of the earning distribution, with the $4.9 \%$ of the bottom quartile volunteering an average of 2.15 hours on the day the time diary was collected, conditional on volunteering, and the $5.2 \%$ of top quartile volunteering an average of 2.14 hours (United States Department of Labor, 2010). Additionally, the 2010 Study of High Net Worth Philanthropy (Center on Philanthropy at Indiana University, 2010), surveying individuals with household incomes over $\$ 200,000$ and/or a non-residential net worth over one million dollars, found that nearly $80 \%$ of these individuals with volunteered in a given year, with half that number volunteering over 200 hours.
} 
alent amount directly for charity. Subjects perform identical tasks for charity or themselves, ruling out working for charity due to heterogeneous ability or convex preferences over tasks.

We investigate the choices that subjects make when they have the option to donate both time and money; we call these treatments Time \& Money (T\&M). We also vary the relative wages earned for self and charity. We find a strong desire to give via time rather than from earnings; this outcome holds even when the wages earned directly for the individual are $33 \%$ larger than those for the charity. We interpret these findings to be a rejection of a prediction that agents only care about the value of their donation, and not the manner in which it was given. Our findings are consistent with a model of charitable giving in which volunteering produces more warm glow than monetary donations. A structural model with a constant elasticity of substitution framework rejects the null hypothesis of equal utility for equivalent gifts of time and money. It can, however, rationalize our alternative functional form where gifts of time have greater value.

We also decompose Time \& Money, restricting subjects to donate only their time (Time Only) or earnings (Money Only). We use these treatments as counterfactuals for conditions in which subjects can give both time and money. We find that subjects are much more likely to donate (extensive margin) and give more (intensive margin) when working directly for the charity than when working for themselves and then later donating their earnings to charity, even though the end result of both activities is identical. Our conclusions are unaffected by the corrections for multiple hypothesis testing proposed in List et al. (2016). 
The main implications of our findings are clear: this behavior is inconsistent with any model that assumes equivalent utility for gifts of time and money. An alternative model in which gifts of time produce greater utility than money fits all of our main results.

Of course, volunteering activities in the field have a number of attributes that are different from work. When an individual volunteers for charity, she may see the grateful faces of others, receive greater recognition for her contribution, make valuable social contacts, or perform a task so different from her work that she may view it as leisure. In particular, the ability to signal one's generosity has been show to exert a strong impact on giving behavior. ${ }^{2}$ We readily concede these issues. However, the fact that we find an effect at all in this environment strongly supports the idea that an individuals' preference to volunteer results from more than just these factors. One may argue - though it is not necessary to interpret our main results - that these features increase the utility individuals receive from volunteering relative to donating money in the field and our results are therefore a lower bound for the overall preference for volunteering. ${ }^{3}$

Our model and results have broader applications to the literature on efficiency in general gift-giving (Waldfogel, 1993) and the relationship between financial rewards and altruistic behavior (Lacetera and Macis, 2010). The context of giving and volunteering provides more evidence on how non-monetary donations differ from monetary

\footnotetext{
${ }^{2}$ See, for example, Harbaugh (1998a,b), Li and Riyanto (2009), Samek and Sheremeta (2014), and Kessler (2013) for evidence from observational data, lab experiments, and field experiments.

${ }^{3}$ Alternatively, the ability for higher earners to deduct donations on their tax returns, which are not present in our experimental environment either, might give individuals a preference for monetary donations in the field through a lower price of giving.
} 
ones - not only from the perspective of the recipient, but for the donor as well. Differential warm glow, in addition to social norms around cash gifts (Waldfogel, 2002) and efforts to signal generosity (Ellingsen and Johannesson, 2009), can help reconcile seemingly-inefficient giving behavior.

Our results also have implications for non-profit organizations, which rely on donations of both money and time. Moreover, though both types of donations are common, ${ }^{4}$ the vast majority of the literature on charitable giving addresses aspects of monetary donations exclusively. Volunteering is an important activity in its own right, and deeper investigation of the motivations behind it are warranted.

The remainder of the paper is organized as follows: In Section 2 we present the relevant literature. Section 3 presents the theoretical framework and Section 4 discusses our experimental design and our predictions. Section 5 presents our results, with Section 6 presenting alternative explanations for our main results. Section 7 closes our paper with a brief discussion of our work and concluding remarks.

\section{Literature}

The charitable giving literature discusses warm glow, prestige, reciprocity, fairness, social pressure, and impact philanthropy as potential explanations for the prevalence of pro-social activity. A detailed discussion of the economics of philanthropy is presented by Andreoni (2006). None of these theories invalidates another and each

\footnotetext{
${ }^{4}$ In 2010, approximately 8.1 billion hours of volunteering were provided in the United States (Corporation for National \& Community Service, 2011) with an estimated market value of nearly $\$ 173$ billion. Total monetary gifts to charitable organizations were $\$ 291$ billion (Giving USA Foundation, 2011).
} 
likely underlies some important aspect of individual behavior. For the purpose of our paper, we focus on warm glow as the primary reason for giving, since our experimental design normalizes many of the other factors which could drive pro-social behavior, while also investigating the role of solicitation.

Andreoni (1989) lays out a model in which an agent gains utility from the act of donating, dubbed "warm glow." A number of experiments have documented the extent to which warm glow drives giving. Crumpler and Grossman (2008) show that agents will give some of their own money to charity even when their donation does not alter the total amount donated to charity. That is, individuals are giving for pure warm glow reasons, not to expand the amount available to the charity. Tonin and Vlassopoulos (2010) finds similar influences of impure altruism. Null (2011) suggests warm glow may be partially to blame for inefficient allocations of gifts to charity. ${ }^{5}$ Taken together, these studies indicate that warm glow is a key factor in both charitable activities.

The literature on the relationship between volunteerism and monetary donations consists of theoretical, empirical, and experimental approaches, but even with the various techniques there is no consensus on whether volunteering is a substitute or a complement to a monetary donation. Duncan (1999) develops a model showing that agents should be indifferent between giving time or money to charity in equilibrium. Brown and Lankford (1992) assume that giving is a normal consumption good and use survey data and jointly estimate giving functions of time and money, finding that gifts of time and money are complements. Likewise, Apinunmahakul et al. (2009)

\footnotetext{
${ }^{5}$ The observed inefficient allocations in his study are driven by failures to adequately adjust to different exogenous donor matching rates.
} 
conduct similar analysis with a later and larger survey data and find similar results. Conversely, Bauer et al. (2013) use repeated cross-sectional European survey data; they do not find that donations of time and money are gross complements. Feldman (2010) uses a well-specified utility function to build an econometric model and, using national survey data, shows that the two types of gifts are substitutes.

Lilley and Slonim (2014) conduct a laboratory experiment which offers insights into impure and pure altruism. Subjects make choices about how time and money they would like to donate to charity while facing different match rates, wages, tax rates, and endowments; one of these choices is then implemented. They additionally vary how the value of these donations is phrased in order to induce a focus on pure or impure altruism. Their results, complementary to ours, find that subjects are willing to sacrifice efficiency in their giving in order to increase their own utility.

\section{Theoretical Model}

We develop a model that generates testable implications on how agents view donations of time and money. Following Duncan (1999), we define an increasing, differentiable, quasiconcave utility function for personal consumption and charitable gifts of time and money,

$$
U(x, d, \tilde{w} v) \quad \text { s.t. } \quad x+d+w v=w T
$$

where $x \in \mathbb{R}_{+}$personal consumption, $d \in \mathbb{R}_{+}$the amount of money donated, $v \in \mathbb{R}_{+}$

the time volunteered, $w$ is the earned wage rate and $T$ is the total endowment of 
time. $^{6}$

It is unclear whether an agent views her gift of time to charity at the level of its impact $\left(w^{\prime}\right)$ or at her opportunity cost $(w)$. We define $\theta \in\{0,1\}$ and $\tilde{w}=$ $(1-\theta) w+\theta w^{\prime}$ to determine the wage rate at which the agent views her contribution of non-leisure time, remaining agnostic of how the two wages impact the warm-glow utility of volunteering. ${ }^{7}$ As pointed out in Andreoni et al. (1996), it is likely the case that $w^{\prime} \leq w$.

Our central line of inquiry is the relationship between the types of gifts and their respective warm glow impacts. The conventional assumption is that individuals are indifferent between giving a certain amount of money or of time as long as their desired amounts are given (Andreoni et al., 1996; Duncan, 1999). We consider a strong form and a weak form of this general assumption.

Assumption 1A (Strong Form of Donative Equivalence). Donations of time and money are always perfect substitutes. That is for every utility function $U(x, d, \tilde{w} v)$, there exists a function $\bar{U}$, such that $U(x, d, \tilde{w} v)=\bar{U}(x, d+\tilde{w} v)$.

A weaker assumption assumes that equivalent value given to charity, whether through gifts of time or money, has equal impact, holding all else constant.

Assumption 1B (Weak Form of Donative Equivalence). Holding all else equal, the

\footnotetext{
${ }^{6}$ Previous versions of our paper also included terms for leisure and solicitation. In the interest of simplicity, we omitted those terms in this model. They did not appreciably change theoretical results. See Brown et al. (2013) for the full model. We do discuss the role of solicitation in relation to our specific experimental environment in Section 6.

${ }^{7}$ Note that if we expand the model to allow $\theta \in(0,1)$, predictions will be similar to the case where $\theta=1$. Essentially, this is equivalent to increasing the curvature of the utility function as agents are less responsive (but still somewhat responsive) to relative price changes.
} 
utility from contributions of equivalent values of time and money are equal. That is, for any, $x, d$, and $v$, and for some $\tilde{w}, U(x, d, \tilde{w} v)=U(x, \tilde{w} v, d)$.

Note that the conditions of the Weak Form of Donative Equivalence necessarily include the Strong Form. However, Assumption 1B also allows the possibility that warm glow is not constant across contribution levels. That is, an individual with preferences for volunteering may still donate due to diminishing marginal returns of the latter activity.

Assumptions 1A and 1B do not, however, directly imply an agent is indifferent between giving time or money to charity. Since it is likely that $w>w^{\prime}$, agents may value their own volunteered time more highly than the charity does if $\tilde{w}$ is weighted toward opportunity cost of time. We develop a proposition that addresses whether the majority of gifts are from time or money.

Proposition 3.1. Suppose the Weak Form of Donative Equivalence holds. Provided some form of donations occur $(d+v \tilde{w}>0)$, the relation between wage rates ( $w$ and $\left.w^{\prime}\right)$ determines the optimal allocation of gifts. Specifically, agents' giving favors the method with the higher wage rate. That is,

1. If $\theta=1$ and $w>w^{\prime}$, then the optimal allocation has $d>v w^{\prime}$.

2. If $\theta=1$ and $w<w^{\prime}$, then the optimal allocation has $d<v w^{\prime}$.

3. If $\theta=1$ and $w=w^{\prime}$, then an optimal allocation exists where $d=v w^{\prime}$. If $U$ satisfies strict concavity, this allocation is unique.

4. If $\theta=0$, then an optimal allocation exists where $d=v w$. If $U$ satisfies strict concavity, this allocation is unique. 
Proof. See Appendix A

Thus, if effective charitable wage is higher than the wage rate, a majority of gifts should come from volunteering. If the opposite occurs, the majority of gifts should be from monetary donations. If the wages are equal, an optimum allocation will exist where donations will be equal. That optimum will be unique if strict concavity is satisfied. Since the Strong Form necessarily violates strict concavity, we can expect multiple optimal allocations when wage rates are equal under that assumption.

It is interesting to note if we have multiple optimal allocations under the conditions of parts 3 and 4, the Weak Form implies that all optimal allocations will be symmetric about $d=v \tilde{w}$. If $\left(x^{*}, d^{*}, v^{*} \tilde{w}\right)$ where $d^{*} \neq v^{*} \tilde{w}$ is optimal, then $\left(x^{*}, v^{*} \tilde{w}, d^{*}\right)$ is optimal as well, because $U\left(x^{*}, d^{*}, v^{*} \tilde{w}\right)=U\left(x^{*}, v^{*} \tilde{w}, d^{*}\right)$ and both allocations are on the budget constraint. One can therefore consider the "average" optimal allocation $d=v \tilde{w}$ regardless of whether strict concavity holds. Since we observe the behavior of many subjects and compare aggregate outcomes in our experiment, this result is useful in making our theoretical predictions.

Proposition 3.1 provides a corollary which is of interest when only one type of donation (either time or money) is possible.

Corollary 3.1. Assume the Weak Form of Donative Equivalence holds. Suppose that, in one state, monetary donations are restricted so $d_{1} \equiv 0$ and in another state, volunteering is restricted so $v_{2} \equiv 0$. Further suppose $w=w^{\prime}$ and all other parameters are equal across states. If $\left(x_{1}^{*}, 0, v_{1}^{*}\right)$ is an optimal allocation in state 1 , then $\left(x_{1}^{*}, d_{2}^{*}, 0\right)$ is an optimal allocation in state 2 where $v_{1}^{*} w^{\prime}=d_{2}^{*}$.

Proof. See Appendix A 
Corollary 3.1 tells us that an equivalent statement of Proposition 3.1, points 3 and 4 , holds when comparing across theoretical environments. ${ }^{8}$ If wages are equal across two environments - one where only volunteering is possible and one where only monetary donations are possible - then donations should be equal.

Another comparison can be made between states where only one form of donations are permissible and states with both, provided the Strong Form holds. No equivalent prediction can be made under the Weak Form.

Proposition 3.2. Assume the Strong Form of Donative Equivalence holds. When $w=w^{\prime}$, giving in an environment with at least two methods of giving available, total gifts are equal to giving in an environment where only one method of giving is available, ceteris paribus.

Proof. See Appendix A

The main contention of this paper is that assumption of donative equivalence between money and time - whether in the strong or weak form - does not explain our motivating example or empirical data on charitable giving particularly well. As an alternative, we propose an alternative assumption that gifts of time produce greater warm glow than money. We modify the Weak Form slightly to produce Assumption $1 \mathrm{C}$.

Assumption 1C (Alternate Form). Holding all else equal, the utility from contributions of time exceed that from money. That is, for any, $x$, $d$, and $v$, and for some $\tilde{w}, U(x, d, \tilde{w} v) \gtreqless U(x, \tilde{w} v, d)$ if and only if $\tilde{w} v \gtreqless d$.

\footnotetext{
${ }^{8}$ Points 1 and 2 will also hold across such theoretical environments.
} 
Under the Alternate Form, some of the preceding results no longer hold. Appendix section A.4 provides modified forms of Propositions 3.1 and Corollary 3.1. The conditions of Proposition 3.1, parts 3 and 4 now produce $d<v w^{\prime}$ and $d<v w$, respectively. Corollary 3.1 now implies $v_{1}^{*} w^{\prime}>d_{2}^{*}$. Proposition 3.1, part 2 remains unchanged. The conditions of of Proposition 3.1, part 1 lead to no result under the Alternate Form.

This theoretical environment generates testable implications regarding the allocations of both types of gifts and two- versus one-gift environments under all three forms of our donative assumptions. In the next section, we explain our experimental design and then discuss, in Section 4.5, the specific predictions that these implications produce in this experiment.

\section{Experimental Design and Predictions}

The experiment consisted of subjects selecting one of ten charities, performing an effort task to earn money that ultimately would go to themselves or charity, and then observing the experimenter allocate cash according to their decision. Subjects encountered the same list of charities in randomized order. The content and length of the effort task as well as the payment procedures were identical across subjects. Importantly, subjects earned all the money they donated to charity rather than receiving it as an endowment; this design allows for a clearer comparison to our treatments where subjects can choose to work directly for charity and may also more 
accurately model outside behavior. ${ }^{9}$

\subsection{Charity Selection}

Subjects were informed they would have to select one charity from a menu of ten charities and corresponding descriptions. Charities were randomly sorted on the screen into one of two different menu styles, organized either by location (local or national) or by type of charity (e.g. food security, special needs, etc.). The order of the relevant categories was randomized, as was the order of charities within each category. This was done to assuage concerns of anchoring effects from specific menus; an example menu can be seen in Figure 1. Subjects were given four minutes to review the options available to them and select their charity. ${ }^{10}$ Each subject knew that her choice was finalized once selected and understood that selection of a charity did not require compulsory contribution to it. After all subjects selected a charity, the experiment would proceed.

Some subjects were given information detailing if the charities were approved by either the State Employee Charitable Campaign of Texas or were three or four star rated by Charity Navigator during the charity selection process (Brown et al., forthcoming). This information was provided independently of giving and volunteering treatments and did not impact the results. ${ }^{11}$

\footnotetext{
${ }^{9}$ Reinstein and Riener (2012) show there are large differences in donation behavior when subjects are endowed with money rather than earning their endowment. They find that those subjects who earned their compensation choose to donate less.

${ }^{10}$ This process rarely took more than two minutes.

${ }^{11}$ Indicators for the interaction of our baseline treatments with these information-provision treatments were not jointly or individually statistically significant, whether entered separately for each rating organization $(\mathrm{p}=0.31)$ or together $(\mathrm{p}=0.97)$.
} 


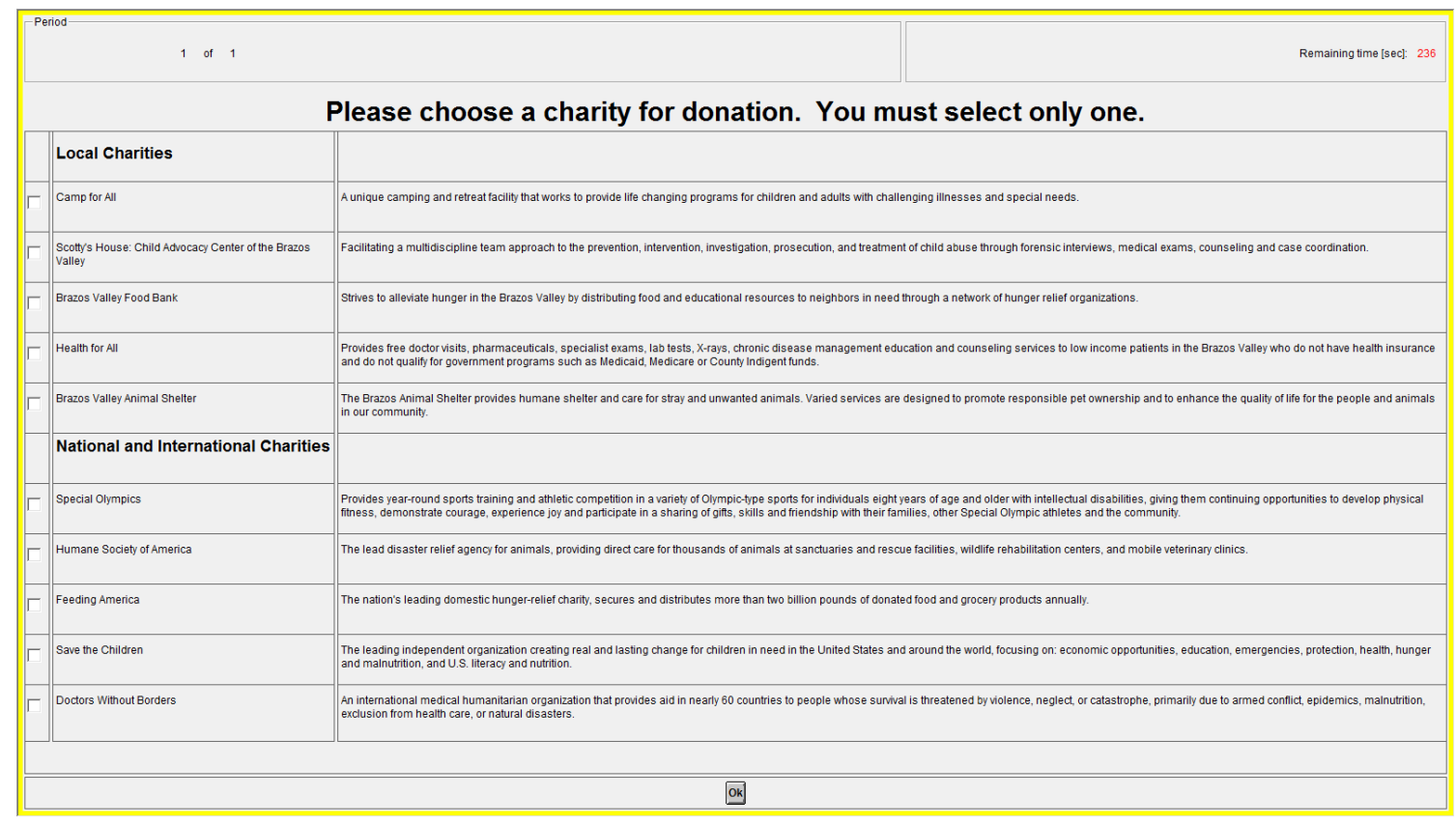

Figure 1: Sample Charity Selection Menu by Location

\subsection{Effort Task and Payment Schedule}

After subjects selected their charity, they began an effort task. Subjects had 75 minutes to move as many "sliders" from one position on the screen to a specific randomized target (see Figure 2) as they could. ${ }^{12}$ Subjects were paid a fixed amount per slider completed in addition to a participation award of $\$ 5.00 .^{13}$

Subjects moved their slider markers along the line to a randomly generated target number (an integer in the set $[1,99]$ ), with the slider beginning at the far left at the point corresponding to 0 . In Figure 2, the target position is located at 73 and the subject's current position is at 63 . Once the subjects aligned their markers, they (or their charity, if applicable) were credited the appropriate wage and they were able

\footnotetext{
${ }^{12}$ This task was developed by Gill and Prowse (2012).

${ }^{13}$ Subjects were not permitted to give their participation award to charity during the experiment.
} 


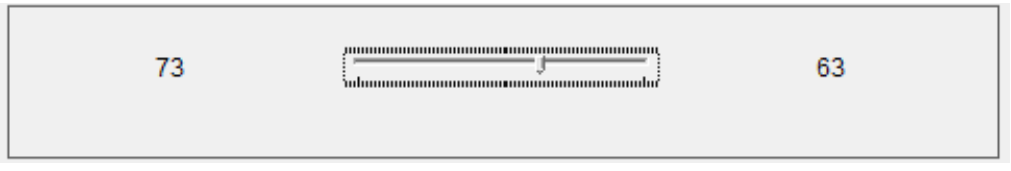

Figure 2: An Example Slider

to move to another slider.

The subject saw thirty sliders (ten rows of three) on the screen and could complete the sliders in any order; once all thirty sliders were finished, the page reset with thirty more sliders and newly randomized target numbers for each slider. This process repeated throughout the experiment until the time expired, providing no upper bound on the amount of money subjects could earn. Subjects who did not wish to participate in this task for the full length of time were allowed to browse the internet. An earnings summary and the time remaining were displayed at the top of the screen, and subjects were given a verbal notification when two minutes remained and when thirty seconds remained.

\subsection{Payment}

Subjects were paid individually and discretely in cash at the conclusion of the experiment to avoid any social stigma from their earnings and donation selection. Subjects were presented two envelopes; one envelope was unlabeled and contained their personal earnings while the second was labeled with the charity's name. If a subject chose to donate money to charity, the second envelope would contain that amount of money. Each subject was asked to confirm that these amounts were correct and sign a form stating that they wished to contribute their charity total to the charity 
whose name was on the envelope. The experimenter then collected the charitable envelope from the subject, taped it shut, and placed the envelope in a box labeled donations. Subjects were informed that all donations would be made within 90 days and were given contact information for the experimenter making the donation. Donation totals for each charity were calculated, and a donation in that amount was given to each charity at the conclusion of all the sessions.

All experiments took place at the Economic Science Laboratory in the Department of Economics at Texas A\&M University. 414 undergraduates were recruited from econdollars.tamu.edu, an ORSEE (Greiner, 2004) website database. Experiments were conducted using z-tree (Fischbacher, 2007) and lasted no longer than two hours, with average subject earnings of $\$ 33.29$. On average, subjects allocated $\$ 4.70$ to charity.

\subsection{Design and Treatments}

The experimental design made use of three primary treatments to determine the effects of donations of time versus money: Time \& Money (T\&M), Time Only (T), and Money Only (M). T\&M examined the situation when individuals can give money or time to charity; wages were varied inside of this treatment to investigate the strength of preferences for and substitution between the two types of gifts. $\mathrm{T}$ and M decomposed this main treatment into its component parts, allowing subjects to either donate their time $(\mathrm{T})$ or their money $(\mathrm{M})$, but not both. ${ }^{14}$

\footnotetext{
${ }^{14}$ Two other treatments, Money (Continual) and Money (at End), were implemented to ascertain whether actionable and/or non-actionable solicitation can explain the strong preferences for donating time rather than money. These are discussed in Section 6, with fuller details regarding these treatments found in Appendix B.
} 
Table 1: Treatments

\begin{tabular}{|c|c|c|c|c|}
\hline Treatment & $\begin{array}{c}\text { Rate Earned } \\
\text { when Working } \\
\text { for Self }\end{array}$ & $\begin{array}{c}\text { Rate Earned } \\
\text { when Working } \\
\text { for Charity }\end{array}$ & $\begin{array}{l}\text { Opportunity to } \\
\text { Give Money } \\
\text { Directly }\end{array}$ & $\begin{array}{l}\text { Opportunity to } \\
\text { Give Time } \\
\text { Directly }\end{array}$ \\
\hline T\&M $3 / 3$ & 3 cents & 3 cents & End of Task & During Task \\
\hline T\&M 3/4 & 3 cents & 4 cents & End of Task & During Task \\
\hline $\mathrm{T} \& \mathrm{M} 4 / 3$ & 4 cents & 3 cents & End of Task & During Task \\
\hline $\mathrm{T}$ & 3 cents & 3 cents & None & During Task \\
\hline $\mathrm{M}$ & 3 cents & - & End of Task & None \\
\hline T\&M 3.5/3.5 & 3.5 cents & 3.5 cents & End of Task & During Task \\
\hline $\mathrm{MC}$ & 3 cents & - & During Task & None \\
\hline MR & 3 cents & - & End of Task & None \\
\hline
\end{tabular}

\subsubsection{Time \& Money (T\&M)}

In this treatment, the wage rates when working for self and charity were randomly determined for the subject within a session, ensuring that session effects do not drive our results. We denote the differences within the Time \& Money treatments with a $x / y$ designation, where $x$ is the wage for self and $y$ is the wage earned for charity, measured in cents per slider. ${ }^{15}$ Subjects worked for either the charity or for themselves at fixed wages rates. Additionally, they could donate any of the money they earned for themselves to the charity at the end. To minimize default effects, subjects chose whether to start by working for charity or themselves; these buttons were randomized on the screen before the effort task began. The subject would see the button in Figure 3a with the additional message reminding her that she could donate any personal earnings at the end of the effort task, as in Figure 3b.

\footnotetext{
${ }^{15}$ Because the experimenter read the instructions aloud, mixing treatments within a session was impractical. To combat session effects, the same experimenter conducted each session and the time of day for each treatment was randomized.
} 


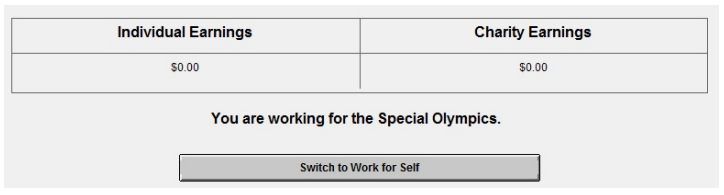

(a) Time, Time and Money

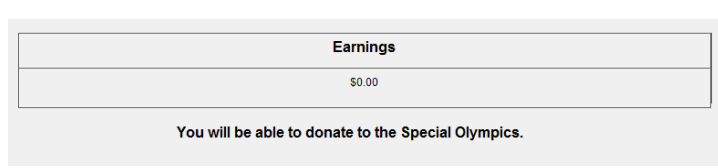

(b) Money Only

Figure 3: Display of Earnings and Donation Opportunities During Effort Task

\subsubsection{Time Only (T)}

The Time Only (T) treatment simulated an agent's choice between working for oneself and volunteering for charity; subjects had the option to have their effort directly accrue to themselves or to the charity. However, there was no option to donate any personal earnings at the end of the effort task. Each subject in the treatment had a button (see Figure 3a) under their earnings display which allowed them to change how their earnings accrue; either the earnings went to the individual or the charity she selected at the beginning of the experiment. As above, subjects chose whether to start by working for the charity or themselves.

\subsubsection{Money Only (M)}

In this treatment, the subjects could only earn money for themselves, but were reminded throughout they they have the option to donate any of their earnings to the charity they initially selected. An example of this reminder can be found in Figure 3b. 


\subsection{Theoretical Predictions}

Our theoretical model provides predictions for subjects' behavior as the wage ratio changes in the Time \& Money treatment. Applying Proposition 3.1 to our experimental environment yields Predictions 1 and 2.

In cases of identical wage rates or perceived identical wage rates $(\theta=0)$, the Weak Form cannot assure a unique optimum allocation unless we assume strict concavity (see Proposition 3.1). However, whatever range of optimal allocations exists, it will be symmetric around $d=v \tilde{w}$. If we make the interpretation that each allocation in this range is equally likely to be chosen by the subject, then the average total of donated money and equivalent volunteering should be equal.

Prediction 1A. If impact of donations rather than opportunity cost matters $(\theta=1)$, we should see more giving by the method favored by relative wage rates. Under each of form of Donative Equivalence,

1. (Strong Form) $\left(\frac{d}{d+v w^{\prime}}\right)_{\frac{4}{3}}=1,\left(\frac{d}{d+v w^{\prime}}\right)_{\frac{3}{4}}=0$.

2. (Weak Form $)\left(\frac{d}{d+v w^{\prime}}\right)_{\frac{4}{3}}>\frac{1}{2}>\left(\frac{d}{d+v w^{\prime}}\right)_{\frac{3}{4}}$.

3. (Alternate Form) $\left(\frac{d}{d+v w^{\prime}}\right)_{\frac{4}{3}}>\left(\frac{d}{d+v w^{\prime}}\right)_{\frac{3}{4}}$ and $\frac{1}{2}>\left(\frac{d}{d+v w^{\prime}}\right)_{\frac{3}{4}}$.

Prediction 1B. If opportunity cost rather than impact of donations matters $(\theta=0)$, relative wage rates should not matter. Under each of form of Donative Equivalence,

1. (Strong Form) An individual subject donation may be in any proportion of time or money. Aggregate donations (in terms of opportunity cost) should be equal in both treatments. 
2. (Weak Form) If $U$ is strictly concave, each subject's donation should be equal in time and money in terms of opportunity cost, $\left(\frac{d}{d+v w}\right)_{\frac{4}{3}}=\frac{1}{2}=\left(\frac{d}{d+v w}\right)_{\frac{3}{4}}$. Otherwise, the predictions of the Strong Form hold.

3. (Alternate Form) Donations of time (in terms of opportunity cost) should be greater in both treatments, $\frac{1}{2}>\left(\frac{d}{d+v w}\right)_{\frac{4}{3}}$ and $\frac{1}{2}>\left(\frac{d}{d+v w}\right)_{\frac{3}{4}}$.

Predictions $1 \mathrm{~A}$ and $1 \mathrm{~B}$ provide valuable tests for determining whether impact or opportunity cost of donations matter to subjects. If relative wages affect the form of subject giving, we can conclude impact matters. If subject behavior is relatively unresponsive to wage rate changes, opportunity cost matters more. The strength of preferences for a method of giving can provide insight into which of our three forms of donative equivalence hold. Further, the results from the equal wage treatment can also help isolate the predictions of the model under each form of these assumptions.

Prediction 2. Provided the utility function is strictly concave, the model under the Weak Form predicts equal donations for time and money for each subject. Greater donations of time are predicted by a model satisfying the Alternate Form.

1. (Strong Form) An individual subject donation may be in any proportion of time or money. Aggregate donations should be equal in both treatments.

2. (Weak Form) If $U(\cdot)$ is strictly concave, $d_{\frac{3}{3}}=v_{\frac{3}{3}}$. Otherwise, the predictions of the Strong Form hold.

3. (Alternate Form) $d_{\frac{3}{3}}<v_{\frac{3}{3}}$. 
Requiring subjects to make their charitable donation exclusively with time or money allows us to further test our model. Prediction 3 applies Proposition 3.2 to a cross-treatment comparison of Money Only, Time Only and Time \& Money.

Prediction 3. Under the Strong Form total donations in the Time $\mathcal{E}_{3}$ Money treatment should be equal to donations in the Time Only and Money Only treatments.

1. (Strong Form) $g_{T \& M}=g_{T}=g_{M}$.

2. (Weak Form) No prediction.

3. (Alternate Form) No prediction.

Comparing the Time Only and Money Only directly provides a clean comparison of our forms of donative equivalence. All preferences that satisfy the Weak Form have the same prediction. In contrast, models under the Alternate Form predict greater donations in the Time Only than Money Only treatment.

Prediction 4. Giving should be equal in the Time Only and Money Only treatments except under the Alternate Form.

1. (Strong Form) $g_{M}=g_{T}$.

2. (Weak Form) $g_{M}=g_{T}$.

3. (Alternate Form) $g_{M}<g_{T}$.

In the next section, we examine how the results of our experiments compare with these predictions. 


\section{Results}

\section{$5.1 \quad$ Experimental Outcomes}

We begin by examining the summary statistics across treatments, in Table 2. There are some differences in effort, as measured by sliders completed, across treatments, though the differences are jointly insignificant. Turning to donative behavior and beginning with the three wage combinations in the Time \& Money treatment, there are few differences in amounts given. Probability of giving $(\mathrm{p}=0.64)$, percent donated $(\mathrm{p}=0.80)$, and probability of giving more than one dollar $(\mathrm{p}=0.86)$ or five dollars $(\mathrm{p}=0.98)$ do not differ across these three treatments. ${ }^{16}$

We now focus on the relative allocations of charitable donations of time and money across treatments as specified in our hypotheses. We first examine Prediction 1 , the relative allocation of donations of time and money when wage rates for each activity are unequal. Given that we examine multiple outcomes across multiple treatments in our predictions, we make use of recent work by List et al. (2016) on multiple hypothesis testing, who note that "[w]ithout taking into account the statistical inference problem arising from multiple testing, experimentalists would be quite likely to undertake a substantially large false discovery risk and draw ungrounded conclusions." In no cases are statistically significant results discussed below negated by the corrections discussed in List et al. (2016).

Result 1. In the Time $\&$ Money treatment, when the wage ratio favors earning

\footnotetext{
${ }^{16} \mathrm{An}$ additional $T \& M_{3.5 / 3.5}$ treatment, included to test for income effects, uncovers no meaningful differences in the percent donated or the ratio of time and money donations relative to $T \& M_{3 / 3}$. These results are shown in Table 5.
} 
Table 2: Summary Statistics

\begin{tabular}{lccccc}
\hline Total Giving & $\begin{array}{c}\text { T\&M } \\
(\mathbf{0 . 0 3} \mathbf{0 . 0 3})\end{array}$ & $\begin{array}{c}\text { T\&M } \\
\mathbf{( 0 . 0 4 , 0 . 0 3 )}\end{array}$ & $\begin{array}{c}\text { T\&M } \\
(\mathbf{0 . 0 3 , 0 . 0 4})\end{array}$ & $\begin{array}{c}\text { Time } \\
\text { Only }\end{array}$ & $\begin{array}{c}\text { Money } \\
\text { Only }\end{array}$ \\
\hline $\mathrm{N}$ & 43 & 45 & 41 & 81 & 48 \\
Sliders Completed & 822.53 & 852.29 & 900.49 & 905.11 & 962.5 \\
& $(203.90)$ & $(244.53)$ & $(279.61)$ & $(263.78)$ & $(238.51)$ \\
Earnings from Effort & 24.68 & 33.16 & 28.3 & 27.15 & 28.88 \\
& $(6.12)$ & $(8.57)$ & $(8.89)$ & $(7.91)$ & $(7.16)$ \\
Percent Giving Any Amount & 83.72 & 75.56 & 80.49 & 71.60 & 31.30 \\
Percent Giving $\$ 1$ or More & 60.47 & 63.41 & 62.22 & 67.90 & 16.67 \\
Percent Giving $\$ 5$ or More & 39.53 & 41.46 & 40.00 & 43.21 & 8.33 \\
Amount Donated & 4.52 & 5.64 & 5.78 & 5.55 & 1.64 \\
& $(5.59)$ & $(7.94)$ & $(6.77)$ & $(6.00)$ & $(5.23)$ \\
Percent Donated & 20.60 & 17.18 & 19.21 & 20.17 & 5.48 \\
& $(25.95)$ & $(23.19)$ & $(20.05)$ & $(20.64)$ & $(16.81)$ \\
\hline Conditional on Giving & & & & & \\
\hline N & 36 & 34 & 33 & 58 & 15 \\
Earnings from Effort & 23.72 & 33.75 & 28.43 & 27.30 & 27.47 \\
& $(6.04)$ & $(9.24)$ & $(9.34)$ & $(8.04)$ & $(6.69)$ \\
Percent Giving $\$ 1$ or More & 72.22 & 82.35 & 78.79 & 94.8 & 53.3 \\
Percent Giving $\$ 5$ or More & 47.22 & 52.94 & 51.52 & 60.3 & 26.7 \\
Amount Donated & 5.4 & 7.47 & 7.18 & 7.76 & 5.26 \\
& $(5.83)$ & $(8.37)$ & $(6.85)$ & $(5.75)$ & $(8.44)$ \\
Percent Donated & 24.6 & 22.74 & 23.87 & 28.2 & 17.5 \\
& $(26.59)$ & $(24.23)$ & $(19.7)$ & $(19.2)$ & $(26.9)$ \\
25th Percentile of Giving & 0.98 & 1.68 & 2.44 & 2.70 & 0.69 \\
50th Percentile of Giving & 4.81 & 5.61 & 5.25 & 6.65 & 1.02 \\
75th Percentile of Giving & 7.57 & 10.12 & 11.84 & 10.95 & 5.38 \\
\hline
\end{tabular}


directly for charity, nearly all donations are of time. When the wage ratio favors monetary donations to charity, the donations are roughly evenly split between time and money.

Figure 4 shows the percent of giving from money and time under the different wage rates in the Time \& Money treatment. Consistent with a warm-glow model where the impact of donations determine warm glow $(\theta=1$, see Prediction 1A), a larger proportion of donations come from money than time under $T \& M_{4 / 3}$ than $T \& M_{3 / 4}$, when the relative wage rate for own earnings increases $(\mathrm{p}=0.001)$. Specifically, $10.5 \%$ of donations are in the form of money when the relative wage favors donating time in $T \& M_{3 / 4}$, and $47.5 \%$ of the donations are of money when the relative wage favors donating money in $T \& M_{4 / 3}$. Under the Strong Form of Donative Equivalence, these proportions should be 0 and 1, respectively, as seen in Prediction 1A. The Weak Form, on the other hand, predicts that a majority of donations should be in the form favored by relative wage rates; this is only partially consistent with the data. These data are, on the other hand entirely consistent with the prediction of the Alternate Form.

It difficult to reconcile the preceding results with a model of charitable giving where agents value donations of time at their opportunity $\operatorname{cost}(\theta=0)$. In such a model, even without strict concavity (which would predict all subjects to give equal amounts), we would expect roughly equal numbers of subjects to make a greater proportion of their donations by each method. We expect this result because if subjects have preferences that make them indifferent among several optimal allocations, those allocations must be symmetric about $d=v w$ under the Weak Form. This prediction 


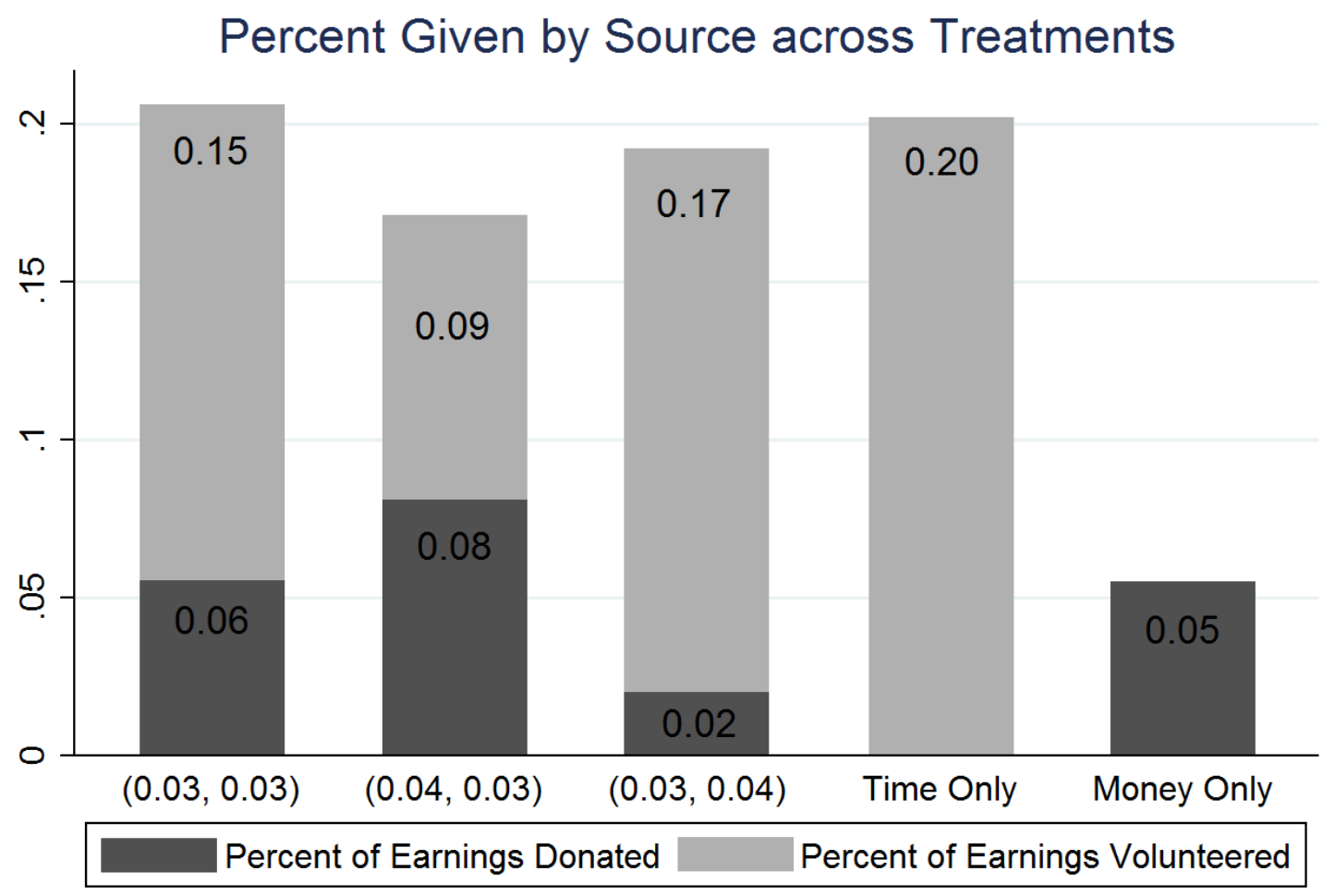

The Time and Money Conditions are in (Ind Wages, Charity Wages)

Figure 4: Giving by Source of Gift

is not consistent with our data. Valuing volunteering at its opportunity cost (vw), we find 18 subjects give more time than money and 5 subjects give more money than time in the $T \& M_{3 / 4}$ treatment; 15 subjects give more time than money and 18 give more money than time in the $T \& M_{4 / 3}$ treatment. This difference is significant at $p<0.01$.

Result 2. When the relative wage ratio is equal in the $T \& M_{3 / 3}$ treatment, a majority of donations are in the form of time.

Figure 4 also shows relative donations in $T \& M_{3 / 3}$. Here, the relative benefits to 
the charity from a time or money donation are equal. In such cases, Prediction 2 states that under both the Weak and Strong Forms of Donative Equivalence, aggregate totals of giving will be equal across the two methods. Under strict concavity on $U$, each subject's donation should be equal across the two methods. But the split is significantly different from equal in $T \& M_{3 / 3}(\mathrm{p}=0.03)$, with roughly three-fourths of donations made through volunteering. Further observing the decisions of individual subjects, 25 gave more through time than money, 11 gave more through money than time. A binomial test finds this difference significant $(p=0.03)$, providing further evidence against the predictions of a model that satisfies the Strong or Weak Forms of Donative Equivalence.

The result is consistent with Prediction 2 under the Alternate Form. Here, higher levels of volunteering are directly attributable to subject preference for donations of time over money.

Result 3. There is no difference in giving between the Time 8 Money (with equal wage ratio) treatment and the Time Only treatment. There is a difference in giving between the Time 8 Money (with equal wages) treatment and the Money Only treatment.

As seen in Figure 5, the probability of giving at all is slightly higher in $T \& M_{3 / 3}$ than in Time Only $(\mathrm{p}=0.14)$, though there are no significant differences in giving over one dollar $(\mathrm{p}=0.57)$ or over five dollars $(\mathrm{p}=0.70)$. A Kolmogorov-Smirnov test finds no difference in the two distributions $(\mathrm{p}=0.39) .{ }^{17}$ On the other hand,

\footnotetext{
${ }^{17}$ Our suspicion is that the slightly higher rate of small gifts in $T \& M_{3 / 3}$ is due to an aversion to receiving coins in payment (see Fielding and Knowles (2015) for a recent experiment showing that
} 


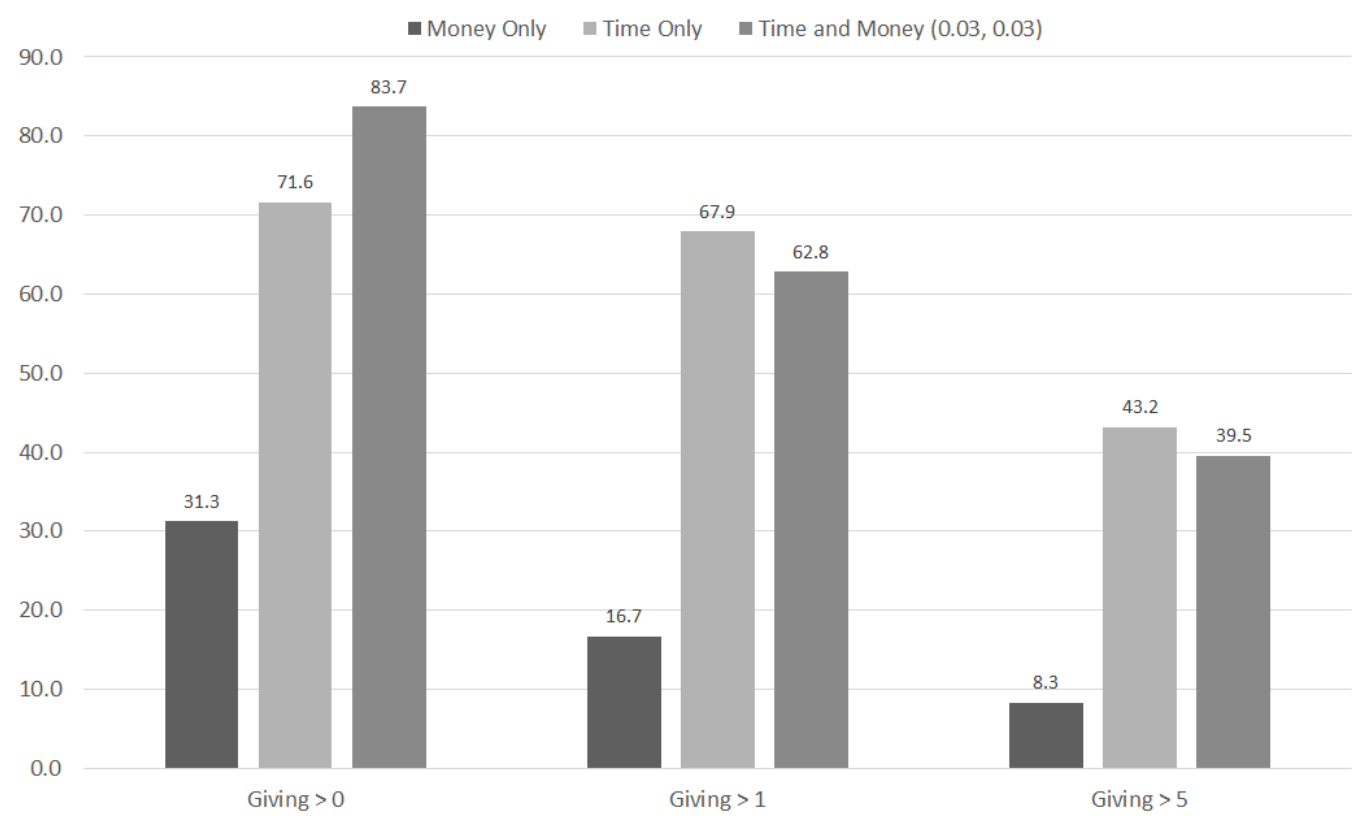

Figure 5: Probability of Giving above Various Thresholds by Treatment

there is significantly more giving in $T \& M_{3 / 3}$ than Money Only.

The preceding results are partially consistent with the Strong Form model in Prediction 3 as we cannot reject $T \& M_{3 / 3}=T$, but the combined hypotheses $T \& M_{3 / 3}=$ $M, T$ are rejected at $p<0.01$. Thus, we conclude that Result 3 is not consistent with the predictions of a model where the Strong Form of Donative Equivalence holds.

Finally, we examine donations in the Time Only and Money Only treatments. Recall that Prediction 4 states that contributions should be equal across treatments as long as a model satisfies the Weak Form of Donative Equivalence.

Result 4. Subjects in Time Only treatment donate more resources to charity than

subjects donate more to charity when their payment is in the form of loose change). This conjecture is confirmed in the data: a number of donors in $T \& M_{3 / 3}$ gave only enough to leave themselves with an even amount. The distributions of giving behavior are quite similar otherwise. 
in Money Only.

As discussed in Section 4, our stylized experiment eliminates many of the other rewards to volunteering. The magnitude and significance of these results, with the total percent accruing to charity significantly different at $p=0.0001$, are further evidence against Prediction 4 under the Strong and Weak Form of Donative Equivalence. Giving effort directly, akin to volunteering, provides more warm glow than donating money. Even when individuals are faced with environments which offer identical wages, social pressure, and so on, donative behavior is starkly different when all that changes is whether they can give time or money to the charity.

Result 4 directly contradicts Prediction 4 under the Strong and Weak Forms and is inconsistent with the result of Corollary 3.1. However, a model of warm glow under the Alternate Form - where gifts of time produce greater warm glow than gifts of money - is consistent with all the results: giving changes with relative wages; more gifts of time occur when wages are equal; total giving is substantially higher when both time and money are options for donations than when only money is an option; and giving is higher when volunteering is the only option relative to when only gifts of money are possible.

\subsection{A Structural Model of Giving}

As discussed above, our results are most consistent with the predictions of a warm

glow model under the assumptions of our Alternate Form of Donative Equivalence. We now turn to structural estimation to examine whether we can rationalize these results in a standard utility framework. Importantly, the structural model allows us 
to pinpoint specific parameter values that correspond to our model under the Strong, Weak and Alternate Forms of Donative Equivalence.

We follow Fisman et al.'s (2007) framework, which models subject decisions in a three-person dictator game. We assume a separable utility function which may be expressed in terms of a macro (overall) utility function, allocating between earnings for self and donations, and a subutility function, in which donations are allocated between time and money.

$$
\begin{aligned}
U_{s} & =\left[\alpha(x)^{\rho}+(1-\alpha) \times\left[\alpha^{\prime}\left(\theta w v+(1-\theta) w^{\prime} v\right)^{\rho^{\prime}}+\left(1-\alpha^{\prime}\right)(d)^{\rho^{\prime}}\right]^{\rho / \rho^{\prime}}\right]^{1 / \rho} \\
\text { s.t. } I & =x+d+w v .
\end{aligned}
$$

As in Section 3, the terms $x, v, d \geq 0$ denote money kept by the subject, time effort given to charity, and money given to charity, respectively. The term $\theta \in\{0,1\}$ represents whether the impact $(\theta=1)$ or opportunity $\operatorname{cost}(\theta=0)$ of volunteering affects utility levels. The terms $\alpha, \alpha^{\prime} \in[0,1]$ represent the relative weight on self versus charity and relative weight of donations of time versus money, respectively. Here $\alpha>0.5\left(\alpha^{\prime}>0.5\right)$ represents a preference for keeping earnings for oneself rather than giving to charity (giving in the form of money rather than time); values below 0.5 would indicate the reverse.

The terms $\rho, \rho^{\prime} \in(\infty, 1]$ define the curvature of the indifference curves between earnings for self and gifts for charity and the curvature of the indifference curves for gifts of time and money, respectively. If $0<\rho \leq 1$, agents are concerned with maximizing the total amount of money that goes to charity and themselves - that 
Table 3: Parametric Specifications by Donative Equivalence Assumption

\begin{tabular}{cc}
\hline Model Assumption & Parameter Specification \\
\hline Strong Form & $\alpha^{\prime}=0.5, \rho^{\prime}=1$ \\
Weak Form & $\alpha^{\prime}=0.5, \rho^{\prime} \leq 1$ \\
Alternate Form & $\alpha^{\prime}<0.5, \rho^{\prime} \leq 1$ \\
\hline
\end{tabular}

is, total earnings before any division. Similarly, values of $0<\rho^{\prime} \leq 1$ indicate that agents look to maximize total contributions to charity, with the two types of giving as substitutes. Alternatively, $\rho<0$ implies that agents prefer to reduce inequality between their personal earnings and the amount given to charity, to some extent, even in the face of a reduction in overall earnings. Similarly $\rho^{\prime}<0$ points to a desire to maintain similar amounts of gifts of time and money, suggesting that the two forms of giving are complements. As $\rho, \rho^{\prime} \rightarrow 0$ the indifference curves more closely resemble Cobb-Douglas functions.

As summarized in Table 3, there are clear parameter values that correspond to our assumptions about Donative Equivalence. The Strong Form requires $\alpha^{\prime}=0.5$ and $\rho^{\prime}=1$; the Weak Form requires $\alpha^{\prime}=0.5$ and $\rho^{\prime} \leq 1$; the Alternate Form requires $\alpha^{\prime}<0.5$ and $\rho^{\prime}<1$. The models do require $\alpha$ and $\rho$ to have any specific values.

Using the same econometric approach as Fisman et al. (2007), we estimate these parameters for a single representative subject. ${ }^{18}$ Panels A and B of Table 4 provide estimates based on decisions of all 168 subjects that participated in all variations of our T\&M treatments. Panels $\mathrm{C}$ and D restrict analysis to the 100 subjects in those treatments who gave a positive amount to charity in either form. In each case, we

\footnotetext{
${ }^{18}$ Note that Fisman et al. (2007) had multiple observations per subject at different price levels and estimated parameters for each subject. With only one observation per subject, we estimate our model for a representative subject based on the decisions of all subjects.
} 
Table 4: Structural Parameter Estimates

\begin{tabular}{ccccc} 
& \multicolumn{2}{c}{ All Subjects } & \multicolumn{2}{c}{ Givers Only } \\
& $(1)$ & $(2)$ & $(3)$ & $(4)$ \\
& $\theta=0$ & $\theta=1$ & $\theta=0$ & $\theta=1$ \\
\hline$\alpha$ & 0.586 & 0.948 & 0.652 & 0.976 \\
& {$[0.573,0.658]$} & {$[0.576,1.000]$} & {$[0.524,0.747]$} & {$[0.600,1.000]$} \\
$\alpha^{\prime}$ & 0.643 & -0.445 & 0.182 & -1.870 \\
& {$[0.516,0.719]$} & {$\left[-2.69 \times 10^{13}, 0.636\right]$} & {$[-0.090,0.746]$} & {$\left[-1.71 \times 10^{14}, 0.323\right]$} \\
$\rho^{\prime}$ & 0.176 & 0.442 & 0.176 & 0.442 \\
& {$[0.000,0.374]$} & {$[0.370,0.498]$} & {$[0.000,0.368]$} & {$[0.384,0.491]$} \\
Log likelihood: macro & 0.000 & 0.849 & 0.000 & 0.849 \\
Log likelihood: sub & $-0.032,0.004]$ & {$[0.684,0.987]$} & {$[-0.039,0.006]$} & {$[0.700,0.981]$} \\
Log likelihood: total & -59.9 & -59.9 & -9.4 & -8.9 \\
\hline
\end{tabular}

Each column reports parameter estimates from estimation of the utility function in Equation (2). Bootstrapped $95 \%$ confidence intervals are in brackets. Columns (1) and (2), using all subjects, have $\mathrm{N}=168$. Columns (3) and (4), using only those who made a gift, have $\mathrm{N}=100$.

estimate a specification restricting the utility to be driven by the opportunity cost of volunteering $(\theta=0$, Columns 1 and 3$)$ or impact of volunteering $(\theta=1$, Columns 2 and 4). ${ }^{19}$ We provide estimates and bootstrapped $95 \%$ confidence intervals of $\alpha$, $\alpha^{\prime}, \rho$, and $\rho^{\prime}$.

We briefly discuss the parameters of the macro utility function, $\alpha$ and $\rho$; as noted above, these values do not have a direct bearing on our question. The estimates of $\alpha$, the parameter measuring the value of personal earnings versus gifts to charity, are significantly greater than zero in all specifications. This is unsurprising, as we expect that subjects value their own earnings more than money given to charity.

\footnotetext{
${ }^{19}$ Values of $\theta$ on the interval $(0,1)$ have no theoretical meaning and are not particularly different in practice than $\theta=1$. Essentially, an agent either responds to changes in the relative impact of her donation $(\theta>0)$; or she does not $(\theta=0)$. While values of $\theta$ on the interval $(0,1)$ could reflect a weaker response to changes in the impact of one's donation, those changes are already captured in the $\rho$ term, so accounting for this term is unneccesary.
} 
The estimates of $\rho$ vary depending on the specification. To understand these estimates, recall that both negative $\rho$ (a desire to reduce inequality between personal earnings and charitable gifts) and a low $\alpha$ (a greater preference for charitable gifts) can rationalize high amounts given to charity. When $\theta=1$, a low $\alpha$ predicts that subjects will give large amounts to charity when relative prices favor it; a negative $\rho$ does not require such conditions. But since subjects donating large amounts are seen across all treatments and are no more prevalent in $T \& M_{4 / 3}$, the behavior of these large givers is rationalized through $\rho$. Thus, we observe a very wide confidence interval for $\rho$ when $\theta=1$, as not all subjects give to charity, but a few give a large amount. ${ }^{20}$ When $\theta=0$, relative prices are constant, so a lower $\alpha$ can be used to rationalize that some subjects choose to give high amounts to charity. We therefore see lower $\alpha$ and higher $\rho$ across the two values of $\theta$.

The parameters in the subutility function (i.e., $\alpha^{\prime}, \rho^{\prime}$ ) are of more interest to our central research question, as they represent subject preferences over gifts of time and money. In all four specifications, $\alpha^{\prime}$ is significantly less than 0.5 , indicating a preference for gifts of time over those of money. The values of $\alpha^{\prime}$ are closer to zero when $\theta=0$, when utility is derived from opportunity cost rather than impact. The parameter $\rho^{\prime}$ varies dramatically between the $\theta=0$ and $\theta=1$ specifications, with the values indicating Cobb-Douglas preferences when $\theta=0$. This suggests that subjects are trying to give specific, targeted amounts of time and money which do not depend on the amount given in the other form. The implications of this finding may be minor, since the relative price of time and money donations is always one in

\footnotetext{
${ }^{20}$ This finding is consistent with Fisman et al. (2007) who note that "preferences for giving are very heterogeneous, ranging from perfect substitutes to Leontief."
} 
the case when utility is derived from opportunity cost. If $\theta=1$, and relative prices can vary, the values of $\rho^{\prime}$ are quite high and significantly above 0 , indicating that subjects view gifts of time and money as substitutes. This result is consistent with what we observe in Figure 4.

Taken together, the results of the structural estimation are in line with those from the simple analysis of the experimental data. The confidence intervals on the parameter estimates of $\alpha^{\prime}$ and $\rho^{\prime}$ reject the model under the Strong and Weak Forms of Donative Equivalence. A model under the Alternate Form still fits the data. A model where subjects appear to value donations of time on its impact to the charity rather than the opportunity cost to themselves is more predictive of subject results.

The models presented here are directly fit from data in all four of the T\&M treatments, and the estimates largely confirm in-sample results. They also provide clear predictions for the out-of-sample treatments: because $\alpha^{\prime}$ is significantly less than 0.5 in the model, we expect higher amounts given to charity in the time only treatment than the money only treatment. This is, of course, exactly what we find in Section 5, providing additional evidence for this type of model. ${ }^{21}$

\section{Alternative explanations}

There are several alternative explanations for our results that subvert our hypothesis of differential warm glow. These explanations arise specifically from our experimental environment, rather than generally applying to situations involving charitable giving;

\footnotetext{
${ }^{21}$ The model also predicts that subjects will keep more money for themselves because $\alpha$ is significantly greater than 0.5 . This is a far less exciting prediction, albeit a correct one.
} 
that is, they suggest the subjects' preferences for donating time may be a confound of our design. We address each possibility in turn.

\subsection{Solicitation}

One may argue that subjects in Time Only face different levels of solicitation and opportunities to give than those in Money Only, and that the differences we find in subjects' giving behavior in these two treatments are driven by the structure of the T treatment. ${ }^{22}$ To investigate this question, we consider an additional money-only treatment, Money (Continual), in which the subject can give at any point during the effort task by entering the dollar amount she wishes to give into a box on the screen. That is, a subject is allowed to give as many times as she wishes in the experiment up until the final second.

This environment mirrors the opportunity and pressure to give in Time Only. If subjects derive more utility from giving several times than just once at the end of the experiment, or that habit formation drives multiple donations is what drove our earlier results, we should see the behavioral differences between monetary and time gifts disappear; in both $\mathrm{T}$ and $\mathrm{MC}$, it is possible for a subject to give a little due to social pressure and then develop a giving pattern based on her prior gift(s) (Meer,

\footnotetext{
${ }^{22}$ Solicitation has been shown to have an important impact on donor behavior, making potential donors more likely to donate (Andreoni et al., Forthcoming; DellaVigna et al., 2012; Meer and Rosen, 2011). While most papers on this subject have focused on the charity's choice of fundraising strategy and its reaction to grants (e.g., Andreoni and Payne, 2011), Landry et al. (2006) investigate different solicitation approaches and their impact on giving, and find that individuals are much less likely to given in response to direct mail than to a door-to-door solicitation, but conditional on giving, make larger gifts. Breman (2011) finds that allowing donors to defer an increase in the size of their donation to the future increases giving; in future work, we will investigate the effects of commitment mechanisms by giving subjects the opportunity to set their giving schedule prior to the beginning of the effort task.
} 
2013; Xiao and Houser, 2014).

The results, found in Appendix B, show that donative behavior is stronger in MC than in M, though the effects are driven by small gifts. The data indicate that allowing for giving during the task elicits a higher likelihood of giving, but conditional on giving, the differences in donations are not large. This finding is consistent with those in Meer (2011), in which "the mere act of making a gift alleviates the social pressure [from solicitation], but making a larger gift has no effect." We therefore view actionable solicitation as having some effect on donative behavior, but it does not fully explain the difference in giving patterns between the Time Only and Money Only treatments. ${ }^{23}$

More importantly for our primary result, the differences between MC and T remain large. We can easily reject the hypothesis that these two distributions of gifts are the same with a Kolmogorov-Smirnov test $(\mathrm{p}=0.001)$; indeed, on every metric, $\mathrm{T}$ dominates MC. These are the same results when comparing $\mathrm{T}$ and $\mathrm{M}$; indeed, with the exception of a small number of very generous individuals who gave all or nearly all of their earnings, the distribution of giving for $\mathrm{T}$ is always higher than the other treatments.

One may argue that a comparison of $\mathrm{T}$ and $\mathrm{MC}$ is flawed because the cost to give in Money (Continual) is greater than that in Time Only. In the latter treatment, subjects only push a button to begin donating and again when stopping; conversely, in $\mathrm{MC}$ subjects must choose an amount to donate, enter the amount, and push

\footnotetext{
${ }^{23}$ We also examine the role of "non-actionable" solicitation, in contrast to the "actionable" solicitation in $\mathrm{MC}$, by removing the reminder about the opportunity to give to the chosen charity from M. The results, in Appendix B, do not differ greatly from those in Money Only, suggesting that these sorts of passive reminders do not have a strong effect.
} 
a button. As field literature has shown (Knowles and Servatka, 2014; Meer and Rigbi, 2013; Rasul and Huck, 2010), even a minor cost may greatly reduce charitable donations. If our experiment is a similar environment to the field, these minor costs might explain the difference between the two treatments. The data do provide evidence that subjects do not endure a greater cost per donative action in MC than in $\mathrm{T} .{ }^{24}$ We therefore believe that the difference in behavior between MC and $\mathrm{T}$ does not arise from differences in the cost of making a donation.

\subsection{Momentum}

Another explanation for the increased donations through time rather than money is that our volunteering framework takes advantage of momentum. With a touch of a button, donations become the status quo and subjects must exert effort to stop donating. Status quo bias is widely regarded as an important driver of behavior (Samuelson and Zeckhauser, 1988). In order to avoid a default setting, subjects in treatments that included time donations had to choose whether they would begin donating to themselves or charity before the experiment began; $30.2 \%$ of subjects started the experiment donating to charity in the Time \& Money treatments and $32.1 \%$ began in Time Only. With well over half of subjects beginning by working for themselves, this mechanism could also explain lower giving levels in Time Only

\footnotetext{
${ }^{24}$ The average productivity of subjects in MC declines by about $23 \%$ in minutes in which they make a donation, while subjects in $\mathrm{T}$ see a productivity decline of $16 \%$ in minutes in which they switch the target of their earnings. Moreover, conditional on switching at all, the median subject in $\mathrm{T}$ switches three times, while the median subject in $\mathrm{MC}$ only donates once, usually in the last few minutes of the experiment. The total expected loss from switching among those in $\mathrm{T}$ is 8.1 sliders, while the expected loss from giving is 7.4 sliders for givers in MC; this difference is approximately two cents.
} 
or lower relative giving of time in Time \& Money treatments. A subject could get caught up in working for herself and not donate anything to charity. That is, momentum does not favor working for charity over oneself or vice versa. Further, the data do not appear to support the momentum explanation; as mentioned above, among those who work for charity at all, the median subject switched three times.

\subsection{Miscalculation}

Another possible explanation is that subjects somehow miscalculate and overshoot their desired gift to charity be giving too much effort in the Time \& Money or Time Only treatment, but do not make a similar mistake in any of the other treatments. If this explanation is true, we would expect to see subjects accumulating the bulk of their donations to charity in the early part of the experiment. That is, over the course of the 75 minute experiment, they would regret this initial donation and compensate by switching to earning for themselves towards the end. The data do not support this contention at all, as seen in Figure 6 in Appendix B; effort toward charity in both the Time \& Money and Time Only treatments are distributed almost uniformly over time. We therefore do not find this explanation credible.

The Time \& Money treatment itself provides an even clearer test of this miscalculation hypothesis. With equal wage rates, subjects worried about miscalculation could work entirely for themselves through the 75 minute slider task and then donate their exact desired amount of their earnings to charity. This outcome is not the case; Figure 4 shows that roughly three-fourths of all donations occur through

gifts of time in that treatment. Further, the total amounts given are not different 
between $T \& M_{\frac{3}{3}}$ and $\mathrm{T}$, indicating that subjects are not miscalculating their optimal gift amount by over-giving effort.

\subsection{Loss Aversion}

Loss aversion - in which the utility change from a loss is greater in magnitude than that from an equivalent-sized gain - is a fundamental part of behavioral economics literature (Kahneman and Tversky (1979); see Camerer (2005) for a survey). In this context, time donations could be seen foregone gains, while the earnings accrued for oneself and then given to charity represent losses. Since individuals are loss averse, the utility loss would be greater for a subject giving their earnings to charity than from forgoing an identical amount in potential earnings. Then individuals would be more likely give donations in time rather than money; this is true both in our experimental setting and in actual decisions regarding volunteering and monetary contributions.

In general, it is very difficult to differentiate an explanation of loss aversion from differential warm glow. Under the warm glow mechanism, working for charity produces a greater benefit; with loss aversion, donating money incurs a greater cost. For most applications of a basic model, these two features are mathematically equivalent.

An simple way to test these competing explanations in an experiment would be to have pre-committment where subjects decided whether to donate time or money to charity before they earned anything. In an experiment similar to ours, Lilley and Slonim (2014) use pre-committment, but still find a significant preference for

donations of time. Further, the extent of loss aversion and how it is framed in the 
laboratory experiments is a topic of some controversy (see Plott and Zeiler, 2005). For these reasons, we do not believe that loss aversion is solely responsible for our results.

That being said, loss aversion can have profound affects on donative behavior in the field. Breman (2011) conducts a field experiment designed to reduce loss aversion and induce donors to increase their charitable contributions of money. Donors who are asked to increase their monthly contributions in the future are more likely to do so than donors asked to give immediately. Given this result, it plausible that a gift of a time rather than money might inhibit loss aversion in general and make decision to give time more attractive.

\section{Conclusions}

This paper tests models of altruism in a series of laboratory experiments investigating whether individuals behave more generously when working for directly for charity (volunteering) rather than working for themselves and donating part of their earnings. We have a consistent finding - subjects display a stronger desire to donate time and effort than to donate money, even when the wage structure leads to large efficiency losses when donating time instead of earned money. We further investigate these results by restricting subjects to give only time or money and find the same preferences for gifts of time.

We argue the explanation of differential warm glow for donations of time and money is the best explanation for our main result. All of our experimental results 
are consistent with a standard model that allows for this, which we confirm through structural estimation. Further, explanations of our results that are driven by confounds of our design simply do not match the empirical regularities in our data.

More broadly, differential warm glow may be thought of alternative viewpoint to the frequently discussed economic anomaly of gift-gifting (e.g. Camerer, 1988; Waldfogel, 1993; Prendergast and Stole, 2001; Ellingsen and Johannesson, 2011). In almost all cases, non-monetary gifts are a less efficient use of resources than a direct monetary gift (much like our volunteering example), but they are given far more frequently than monetary gifts. Aside from potential social norms against giving cash, a prevailing explanation is that non-monetary gifts, while inefficient, are more conspicuous and thus have superior signaling properties (Ellingsen and Johannesson, 2011). As our donations to charity are anonymous, and donations of time and money are treated identically by experimenters (i.e., they end up being money in the same envelope), our experiments eliminate these signaling motivations, yet the preference for a non-monetary gift to charity remains. This may indicate individuals use non-monetary gifts rather than monetary gifts in social situations simply because they derive greater pleasure from giving non-monetary gifts, regardless of signaling motivations. Previous experiments were unable to isolate and test these explanations separately. Ellingsen and Johannesson (2009) note that subjects are more willing to sacrifice time rather than money in an ultimatum game, but the structure of that game makes it impossible to disentangle whether social factors or preferences over giving are responsible for that result. An extension of our design could measure the willingness of donations to remain anonymous or become public, helping to clarify 
aspects of signaling in charitable giving.

Given these experimental results, a natural question to ask would be how they might translate to other settings. We suspect that factors like social recognition, enjoyment of the volunteer activity itself, and the salience of one's donation all may increase the utility from donating time to charity rather than money.

Nonetheless, charities must balance the higher willingness of their donors to volunteer with the greater impact of their monetary donations. Unlike in our experiment, where wages for volunteering never fell below $75 \%$ of one's personal wage, it is realistic to think one's actual opportunity cost of time may be substantially greater than the value to the charity of the volunteering activity (as it was in our motivating example of the consultant in the soup kitchen). In such cases, charities still may prefer to solicit monetary donations even if individuals are willing to give (based on their personal costs) considerably less. Another implication of differential warm glow is that individuals will accept a lower wage working in the non-profit sector than a higher wage in the for-profit sector, even though they could donate the difference in income to the charity. ${ }^{25}$ Regardless of its relative impact in these settings, our results strongly suggest economic models must consider the warm glow associated with gifts of time and money as different entities.

\footnotetext{
${ }^{25}$ There is disagreement as to whether those working for non-profits are paid less, all else equal. For example, Ruhm and Borkoski (2003) find no evidence of wage differentials. On the other hand, Preston (1989) finds that those in the non-profit sector earn less, and a recent field experiment by Frank (2012) found that half of workers in an online labor market were willing to accept a lower wage rate to work for an organization with greater "social value."
} 


\section{References}

Andreoni, James, "Giving with Impure Altruism: Applications to Charity and Ricardian Equivalence," Journal of Political Economy, 1989, 97 (6), 1447-1458.

_ , Handbook on the Economics of Giving, Reciprocity, and Altruism, Elsevier,

- and Abigail Payne, "Is crowding out due entirely to fundraising? Evidence from a panel of charities," Journal of Public Economics, 2011, 95 (5-6), 334-343.

_, Justin M. Rao, and Hannah Trachtman, "Avoiding the Ask: A Field Experiment on Altruism, Empathy, and Charitable Giving," Journal of Political Economy, Forthcoming.

_, William G. Gale, and John Karl Scholz, "Charitable Contributions of Time and Money," 1996, July.

Apinunmahakul, Amornrat, Vicky Barham, and Rose Anne Devlin, "Charitable Giving, Volunteering, and the Paid Labor Market," Nonprofit and Voluntary Sector Quarterly, 2009, 38 (1), 77-94.

Bauer, Thomas K., Julia Bredtmann, and Christop M. Schmidt, "Time vs. Money: The Supply of Voluntary Labor and Charitable Donations across Europe," European Journal of Political Economy, 2013, 32, 80-94.

Breman, Anna, "Give more tomorrow: Two field experiments on altruism and intertemporal choice," Journal of Public Economics, 2011, 95, 1349-1357.

Brown, Alexander L., Jonathan Meer, and J. Forrest Williams, "Why do people volunteer? An experimental analysis of preferences for time donations," Technical Report, National Bureau of Economic Research 2013.

_ , , and _ , "Social Distance and Quality Rating in Charity Choice," Journal of Behavioral and Experimental Economics, forthcoming.

Brown, Eleanor and Hamilton Lankford, "Gifts of money and gifts of time: estimating the effects of tax prices and available time," Journal of Public Economics, 1992, 47, 321-341.

Camerer, Colin F., "Gifts as Economic Signals and Social Symbols," American Journal of Sociology, 1988, Suppl., 180-S214. 
_ , "Three Cheers - Psychological, Theoretical, Empirical - for Loss Aversion," Journal of Marketing Research, 2005, 42 (2), 129-133.

Center on Philanthropy at Indiana University, "The 2010 Study of High Net Worth Philanthorpy: Issues Driving Charitable Activities amog Affluent Households," 2010, November.

Corporation for National \& Community Service, "Volunteering in America," www. VolunteeringInAmerica.gov, 2011.

Crumpler, Heidi and Philip J. Grossman, "An experimental test of warm glow giving," Journal of Public Economics, 2008, 92, 1011-1021.

DellaVigna, Stefano, John A. List, and Ulrike Malmendier, "Testing for Altruism and Social Pressure in Charitable Giving," The Quarterly Journal of Economics, 2012, 127 (1), 1-56.

Duncan, Brian, "Modeling charitable contributions of time and money," Journal of Public Economics, 1999, 72, 213-242.

Ellingsen, Tore and Magnus Johannesson, "Time is not money," Journal of Economic Behavior \&5 Organization, 2009, 72, 96-102.

_ and _, "Conspicuous Generosity," Journal of Public Economics, 2011, 95 (9-10), 1131-1143.

Feldman, Naomi E., "Time Is Money: Choosing between Charitable Activities," American Economic Journal: Economic Policy, 2010, 2 (1), 103-30.

Fielding, David and Stephen Knowles, "Can You Spare Some Change For Charity? Experimental Evidence on Verbal Cues and Loose Change Effects in a Dictator Game," Experimental Economics, 2015, 18 (4), 718-730.

Fischbacher, U., "z-Tree: Zurich toolbox for ready-made economic experiments," Experimental Economics, 2007, 10, 171-178.

Fisman, Raymond, Shachar Kariv, and Daniel Markovits, "Individual Prefernces for Giving," The American Economic Review, 2007, 97 (5), 1858-1876.

Frank, Douglas H., "Will employees pay to work for a good cause? Evidence from an online labor market," Working Paper, 2012. 
Gill, David and Victoria Prowse, "A Structual Analysis of Disappointment Aversion in Real Effort Competition," American Economic Review, 2012, 102(1), 469503.

Giving USA Foundation, "Giving USA 2011 Executive Summary," 2011.

Greiner, Ben, "The Online Recruitment System ORSEE 2.0 - A Guide for the Organziation of Experiments in Economics," University of Colgne, Working Paper Series in Economics 10, 2004.

Harbaugh, William T., "The Prestige Motive for Making Charitable Transfers," The American Economics Review, 1998, 88 (2), 277-282.

_ , "What do donations buy? A model of philanthropy based on prestige and warm glow," Journal of Public Economics, 1998, 67, 269-284.

Kahneman, Daniel and Amos Tversky, "Prospect Theory: An Analysis of Decision Under Risk," Econometrica, 1979, 47 (2), 263-292.

Kessler, Judd B., "Announcements of Support and Public Good Provision," Working Paper, 2013, June.

Knowles, Stephen and Maros Servatka, "Transaction Costs, the Oppotunity Cost of Time and Inertia in Charitable Giving," Working Paper, 2014, January.

Lacetera, Nicola and Mario Macis, "Do all material incentirves for pro-social activities backfire? The response to cash and non-cash incentives for blood donations," Journal of Economic Psychology, 2010, 31, 738-348.

Landry, Craig E, Andreas Lange, John A. List, Michael K. Price, and Nicholas G. Rupp, "Toward an understanding of the economics of charity: Evidence from a field experiment," The Quarterly Journal of Economics, 2006, 121 (2), $747-782$.

Li, Jingping and Yohanes E. Riyanto, "Category Reporting in Charitable Giving: An Experimental Analysis," Working Paper, 2009, January.

Lilley, Andrew and Robert Slonim, "Microfoundations and experimental evidence on the price of warm glow," Journal of Public Economics, 2014, 114, 58-74.

List, John A., Azeem M. Shaikh, and Yang Xu, "Multiple Hypothesis Testing in Experimental Economics," NBER Working Paper Series, January 2016, (21875). 
Meer, Jonathan, "Brother, Can You Spare a Dime: Peer Presure in Charitable Solicitation," Journal of Public Economics, 2011, 95 (7-8), 929-941.

_ , "The Habit of Giving," Economic Inquiry, 2013, 51 (4), 2002-2017.

- and Harvey S. Rosen, "The ABCs of charitable solicitation," Journal of Public Economics, 2011, 95, 363-371.

- and Oren Rigbi, "The Effects of Transactions Costs and Social Distance: Evidence from a Field Experiment," B.E. Journal of Economic Analysis 83 Policy, 2013, 13 (1), 271-296.

Null, C., "Warm glow, information, and inefficient charitable giving," Journal of Public Economics, 2011, 95, 455-465.

Plott, Charles R. and Kathryn Zeiler, "The Willingness to Pay-Willingness to Accept Gap, the "Endowment Effect," Subject Misconceptions, and Experimental Procedures for Eliciting Valuations," The American Economic Review, 2005, 95 (3), 530-545.

Prendergast, Canice and Lars Stole, "The non-monetary nature of gifts," European Economic Review, 2001, 45 (10), 1793-1810.

Preston, Anne E., "The nonprofit worker in a for-profit world," Journal of Labor Economics, 1989, 7 (4), 438-463.

Rasul, Imran and Steffen Huck, "Transactions Costs in Charitable Giving: Evidence from Two Field Experiments," The B.E. Journal of Economic Analyisis 86 Policy, 2010, 10 (1), 1935-1682.

Reinstein, David and Gerhard Riener, "Decomposing desert and tangibility effects in a charitable giving experiment," Experimental Economics, 2012, 15, 229240 .

Ruhm, Cristopher J. and Carey Borkoski, "Compensation in the Nonprofit Sector," Journal of Human Resources, 2003, 38 (4), 992-1021.

Samek, Anya Savikhin and Roman M. Sheremeta, "Recognizing contributors: an experiment on public goods," Experimental Economics, 2014, 17 (4), 673-690.

Samuelson, Williams and Richard Zeckhauser, "Status Quo Bias in Decision Making," Journal of Risk and Uncertainty, 1988, 1 (1), 7-59. 
Tonin, Mirco and Michael Vlassopoulos, "Disentangling the sources of prosocially motivated effort: A field experiment," Journal of Public Economics, 2010, 94, 1086-1092.

United States Department of Labor, "United States Bureau of Labor Statistics," American Time Use Survey (ATUS), 2010.

Waldfogel, Joel, "The Deadweight Loss of Christmas," The American Economic Review, 1993, 83 (5), 1328-1336.

_ , "Gifts, Cash, and Stigma," Economic Inquiry, 2002, 40 (3), 415-427.

Xiao, Erte and Daniel Houser, "Sign Me Up! A Model and Field Experiment on Volunteering," Working Paper, 2014, January. 


\section{Appendices: Not for Publication}

\section{A Mathematical Appendix}

\section{A.1 Proof of Proposition 3.1}

Proposition 3.1. Suppose the Weak Form of Donative Equivalence holds. Provided some form of donations occur $(d+v \tilde{w}>0)$, the relation between wage rates ( $w$ and $\left.w^{\prime}\right)$ determines the optimal allocation of gifts. Specifically, agents' donations (either in time or money) favor the method with the higher wage rate. That is,

1. If $\theta=1$ and $w>w^{\prime}$, then the optimal allocation has $d>v w^{\prime}$.

2. If $\theta=1$ and $w<w^{\prime}$, then the optimal allocation has $d<v w^{\prime}$.

3. If $\theta=1$ and $w=w^{\prime}$, then an optimal allocation exists where $d=v w^{\prime}$. If $U$ satisfies strict concavity, this allocation is unique.

4. If $\theta=0$, then an optimal allocation exists where $d=v w$. If $U$ satisfies strict concavity, this allocation is unique.

Proof. Consider the cases where $\theta=1$ and $w \neq w^{\prime}$ which implies $w \neq \tilde{w}$. Suppose $w>w^{\prime}$, but the optimal consumption bundle $\left(x^{*}, d^{*}, v^{*}\right)$ has $d^{*} \leq v^{*} w^{\prime}$. By the Weak Form, there exists a bundle $\left(x^{*}, d^{\prime}, v^{\prime}\right)$ with $d^{\prime}=v^{*} w^{\prime}$ and $v^{\prime} w^{\prime}=d^{*}$ s.t., $U\left(x^{*}, d^{*}, v^{*} w^{\prime}\right)=U\left(x^{*}, d^{\prime}, v^{\prime} w^{\prime}\right)$. Since $d^{\prime} \geq v^{*} w^{\prime}$ and $w>w^{\prime}$, the cost $x^{*}+d^{\prime}+v^{\prime} w<$ $x^{*}+d^{*}+v^{*} w<=w T$. Therefore there exists an $\epsilon>0$ s.t. $U\left(x^{*}+\epsilon, d^{\prime}, v^{\prime} w^{\prime}\right)>$ $U\left(x^{*}, d^{*}, v w^{\prime}\right), U\left(x^{*}, d^{\prime}, v^{\prime} w^{\prime}\right)$ and $\left(x^{*}+\epsilon\right)+d^{\prime}+v^{\prime} w<w T$ which violates $\left(x^{*}, d^{*}, v^{*}\right)$ being the optimal consumption bundle. The identical reasoning shows when $w<w^{\prime}$, we must have $d<v w^{\prime}$.

Now consider items 3 and 4. Using the Weak Form and the definition of a derivative, one can show $\frac{\partial U}{\partial d}(x, d, v w)=\frac{\partial U}{\partial v}(x, v w, d)$. Since wage rates are identical in the maximization problem, first order conditions dictate a maximum occurs where $d=v w$. Under strict concavity, no other maxima could exist because a convex combination of those two maxima would be in the budget set and produce greater utility than either maxima, contradicting the idea that they are maxima. 


\section{A.2 Proof of Corollary 3.1}

Corollary 3.1. Assume the Weak Form of Donative Equivalence holds. Suppose that, in one state, monetary donations are restricted so $d_{1} \equiv 0$ and in another state, volunteering is restricted so $v_{2} \equiv 0$. Further suppose $w=w^{\prime}$ and all other parameters are equal across states. If $\left(x_{1}^{*}, 0, v_{1}^{*}\right)$ is an optimal allocation in state 1 , then $\left(x_{1}^{*}, d_{2}^{*}, 0\right)$ is an optimal allocation in state 2 where $v_{1}^{*} w^{\prime}=d_{2}^{*}$.

Proof. Suppose not, that the optimal consumption bundle in state 1 is $\left(x_{1}^{*}, 0, v_{1}^{*}\right)$ and the optimal consumption bundle in state 2 is $\left(x_{2}^{*}, d_{2}^{*}, 0\right)$, with $v_{1}^{*} w^{\prime} \neq d_{2}^{*}$. Since the cost of both allocations is equal to total income in their respective states, it follows that $U\left(x_{2}^{*}, d_{2}^{*}, 0\right)>U\left(x_{1}^{*}, v_{1}^{*} w^{\prime}, 0\right)$ since the latter allocation would be attainable in state 2. By the Weak Form, $U\left(x_{2}^{*}, 0, d_{2}^{*}\right)>U\left(x_{1}^{*}, 0, v_{1}^{*} w^{\prime}\right)$. But then $\left(x_{1}^{*}, 0, v_{1}^{*}\right)$ cannot be a maximum in state 1 , violating our given.

\section{A.3 Proof of Proposition 3.2}

Proposition 3.2. Assume the Strong Form of Donative Equivalence holds. When $w=w^{\prime}$, giving in an environment with at least two methods of giving available, total gifts are equal to giving in an environment where only one method of giving is available, ceteris paribus.

Proof. Consider the case where only donating money is allowed and $\left(c^{*}, d^{*}, 0\right)$ is the optimal bundle. Then $U\left(c^{*}, d^{*}, 0\right) \geq U\left(c^{\prime}, d^{\prime}, 0\right)$ for all $\left(c^{\prime}, d^{\prime}, 0\right)$ in the budget set. Consider any $d^{\prime \prime}$ and $v^{\prime \prime}$ in the two good case. Since total income is constant across cases, there exists a $d^{\prime}$ in the single good case such that $d^{\prime}=d^{\prime}+v w^{\prime}$. Then all $\left(c^{*}, d^{* *}, w v^{* *}\right)$ where $d^{* *}+w v^{* *}=d^{*}$ are optimal in the two good case since $U\left(c^{*}, d^{* *}, w v^{* *}\right)=U\left(c^{*}, d^{*}, 0\right) \geq U\left(c^{\prime}, d^{\prime}, 0\right)=U\left(c, d^{\prime \prime}, 0\right)$.

\section{A.4 Modified Propositions under Alternate Form}

Proposition 3.1'. Suppose the Alternate Form holds. Provided some form of donations occur $(d+v \tilde{w}>0)$, the relation between wage rates $\left(w\right.$ and $\left.w^{\prime}\right)$ and preference for volunteering determine the optimal allocation of gifts. Specifically, under certain relative wage conditions agents' donations (either in time or money) favor volunteering. That is,

1. If $\theta=1$ and $w>w^{\prime}$, then $d>v w^{\prime}, d<v w^{\prime}$, or $d=v w^{\prime}$.

2. If $\theta=1$ and $w<w^{\prime}$, then $d<v w^{\prime}$. 
3. If $\theta=1$ and $w=w^{\prime}$, then an optimal allocation is where $d<v w^{\prime}$. If $U$ satisfies strict concavity, this allocation is unique.

4. If $\theta=0$, then an optimal allocation is where $d<v w$. If $U$ satisfies strict concavity, this allocation is unique.

Corollary 3.1'. Assume the Alternate Form holds. Suppose that, in one state, monetary donations are restricted so $d_{1} \equiv 0$ and in another state, volunteering is restricted so $v_{2} \equiv 0$. Further suppose $w=w^{\prime}$ and all other parameters are equal across states. If $\left(x_{1}^{*}, 0, v_{1}^{*}\right)$ is an optimal allocation in state 1 , then $\left(x_{1}^{*}, d_{2}^{*}, 0\right)$ is an optimal allocation in state 2 where $v_{1}^{*} w^{\prime}>d_{2}^{*}$. 


\section{B Appendix of Additional Figures and Tables}

Table 5: Summary Statistics for Additional Treatments

\begin{tabular}{lccc}
\hline & $\begin{array}{c}\text { Money } \\
\text { Continual }\end{array}$ & $\begin{array}{c}\text { Money, no } \\
\text { Reminder }\end{array}$ & $\begin{array}{c}\text { T+CR } \\
(\mathbf{0 . 0 3 5}, \mathbf{0 . 0 3 5})\end{array}$ \\
\hline $\mathrm{N}$ & 70 & 47 & 39 \\
Sliders Completed & 911.99 & 886.28 & 856.78 \\
& $(250.33)$ & $(224.64)$ & $(268.41)$ \\
Earnings from Effort & 27.36 & 26.59 & 29.99 \\
& $7.52)$ & $(6.74)$ & $(9.40)$ \\
Percent Giving Any Amount & 57.10 & 31.90 & 74.36 \\
Percent Giving $\$ 1$ or More & 42.86 & 17.02 & 58.97 \\
Percent Giving $\$ 5$ or More & 22.43 & 10.64 & 23.08 \\
Amount Donated & 2.85 & 1.02 & 4.75 \\
& $(5.49)$ & $(2.26)$ & $(9.45)$ \\
Percent Donated & 11.79 & 3.89 & 15.35 \\
& $(22.85)$ & $(9.08)$ & $(25.23)$ \\
\hline Conditional on Giving & & & \\
\hline N & 40 & 15 & 29.56 \\
Earnings from Effort & 24.81 & 27.11 & $(8.73)$ \\
Percent Giving $\$ 1$ or More & $(6.54)$ & $(6.74)$ & 75.86 \\
Percent Giving $\$ 5$ or More & 77.5 & 53.30 & 31.03 \\
Amount Donated & 40.0 & 33.30 & 6.39 \\
& 4.97 & 3.20 & $(10.51)$ \\
Percent Donated & $(6.52)$ & $(3.06)$ & 20.64 \\
25th Percentile of Giving & 21.2 & 12.2 & $(27.41)$ \\
50th Percentile of Giving & 2.30 & $(12.8)$ & 3.21 \\
75th Percentile of Giving & 5.00 & 5.0 .30 & \\
\hline
\end{tabular}




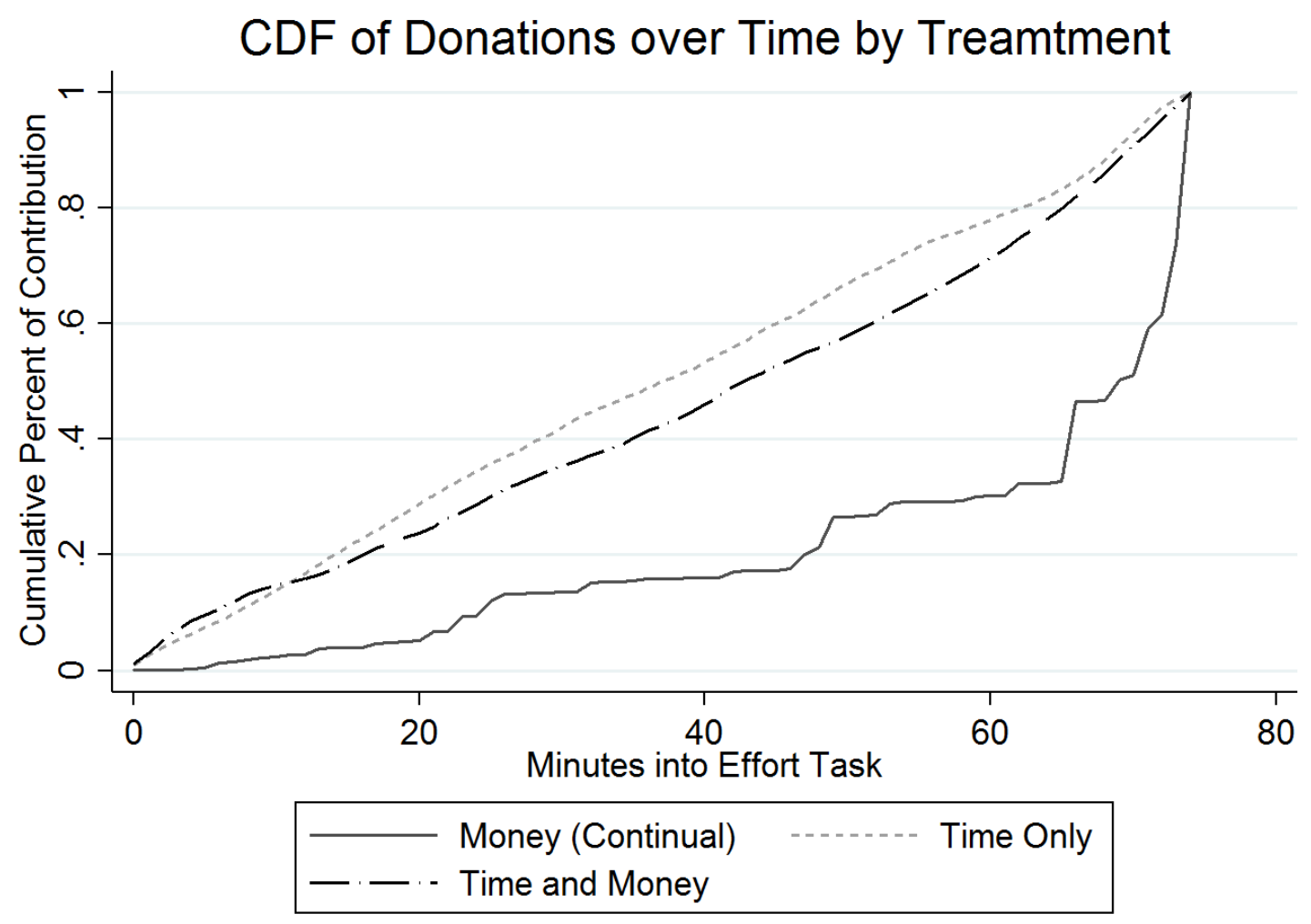

Figure 6: CDF of dollars donated by minute in $\mathrm{T}, \mathrm{MC}$, and $T \& M_{3 / 3}$ 